\title{
Sağlık Bilimleri Fakültesi Öğrencilerinin Bilgi ve İletişim Teknolojilerine Bakışı Üzerine Bir Araştırma: Konya İli Örneği
}

\section{A Research on The View of Information and Communication Technologies of The Students in The Faculty of Health Sciences: Konya Province Example}

\author{
${ }^{1}$ Döne TÜTÜNCÜ, ${ }^{2}$ Yusuf Yalçın İLERI \\ ${ }^{1}$ İstinye Üniversitesi, İktisadi, İdari ve Sosyal Bilimler Fakültesi, Sağlık Yönetimi Anabilim Dalı, İstanbul, Türkiye \\ ${ }^{2}$ Necmettin Erbakan Üniversitesi, Sağlık Bilimleri Fakültesi, Sağlık Bilişimi ve Teknolojileri Anabilim Dalı, Konya, Türkiye
}

Döne Tütüncü: https://orcid.org/0000-0002-4527-8968

Yusuf Yalçın İleri: https://orcid.org/0000-0002-3911-1192

ÖZ

Amaç: Calışma, Sağlık Bilimleri Fakültesi'nde (SBF) lisans öğrenimi gören öğrencilerin Bilgi ve İletişim Teknolojilerine (BİT) yönelik tutumlarını ölçmek, en fazla hangi bilgi teknolojilerini kullandıklarını ve kullanım amaçlarının neler olduğunu belirlemek amacıyla gerçekleştirilmiştir.

Materyal ve Metot: Betimleyici tipte olan araştırmanın örneklemini iki farklı üniversitenin SBF'nde lisans öğrenimi gören 353 öğrenci oluşturmaktadır. Araştırmanın verileri kişisel bilgi formu ile Bilgi ve İletişim Teknolojileri Tutum Ölçeği kullanılarak toplanmıştır. Verilerin değerlendirilmesinde, t-testi, tanımlayıcı istatistikler, ki-kare testi, tek yönlü varyans analizi (ANOVA) ve Tukey posthoc testi kullanılmıştır.

Bulgular: Farklı üniversitelerde öğrenim gören SBF öğrencilerinin BİT'e karşı benzer tutuma $(\overline{\mathrm{x}}=3,48)$ sahip oldukları saptanmıştır. Katılımcıların günlük hayatta yararlandığı bilgi teknolojilerinin en fazla (\%39) cep telefo$\mathrm{nu}$, en az $(\% 2,5)$ dijital oynatıcılar olduğu belirlenmiştir. Öğrencilerin interneti kullanım amaçlarının; en fazla (\% $12,4)$ eğlenmek, en az $(\% 0,1)$ internet üzerinden para kazanmak olduğu saptanmıştır.

Sonuç: SBF öğrencilerinin BİT kullanımına dair olumlu bir tutuma sahip oldukları, internet ve bilgi teknolojileri kullanımının yüksek olduğu tespit edilmiştir.

Anahtar Kelimeler: Bilgi, bilgi teknolojileri, e-iletişim

\section{ABSTRACT}

Objective: The study was carried out to measure the attitudes of the undergraduates in the Faculty of Health Sciences (FHS) towards Information and Communication Technologies (ICT), to find out which information technologies they use the most and for what purpose.

Materials and Methods: The sample of the study, which is in the descriptive type, consists of 353 undergraduate students studying at the two different universities' Faculty of Health Sciences. The data of the research were collected using a personal information form with the Information and Communication Technologies Attitude Scale. T-test, descriptive statistics, chi-square test, one-way analysis of variance (ANOVA) and Tukey HSD post-hoc test were used to evaluate the data.

Results: It was determined that FHS students studying at different universities have a similar attitude $(\overline{\mathrm{x}}=3.48)$ towards ICT. It was determined that the information technologies used by the participants in daily life are mostly mobile phones (39\%) and digital players at least (2.5\%). Internet usage purposes of students; it was determined that having fun the most (12.4\%) and making money online was the least $(0.1 \%)$.

Conclusion: It has been determined that FHS students have a positive attitude towards ICT use, and their use of internet and information technologies is high.

Keywords: E-communication, information, information technologies
Sorumlu Yazar / Corresponding Author:

Döne Tütüncü

İstinye Üniversitesi, Topkapı Kampüsü Zeytinburnu/İstanbul

Tel: +90 - 5413185242

E-mail: done.tutuncu@istinye.edu.tr
Yayın Bilgisi / Article Info:

Gönderi Tarihi/ Received: 16/10/2020

Kabul Tarihi/ Accepted: 15/12/2020

Online Yayın Tarihi/ Published: 05/03/2021

Atıf / Cited: Tütüncü D, İleri YY. Sağlık Bilimleri Fakültesi Öğrencilerinin Bilgi ve İletişim Teknolojilerine Bakışı Üzerine Bir Araştırma: Konya İli Örneği. Online Türk Sağllk Bilimleri Dergisi 2021;6(1):92-101. doi: 10.26453/otjhs.810559 


\section{GÍRIŞ}

İnsanoğlu kendi deneyimlerini kullanarak ve güvenilir kaynaklardan faydalanarak öğrenme ve gelişme ihtiyacını karşılamak amacındadır. Bu istek bireyleri yeni arayışlara yöneltmiş ve teknoloji ile tanışmasına vesile olmuştur. Teknoloji kavramı, insanın çevresini denetlemek ve değiştirmek için ortaya koyduğu araç gereçlerle bunlara dair bilgilerin tamamıdır. ${ }^{1}$ Günümüzde yeni bilgi ve teknolojilerin kullanılması, yeni yöntemlerin tercih edilmesi, bilgi aktarımının gün geçtikçe daha da kolaylaşması ve tüm kademelere ulaşabilmesi nedeniyle toplumumuz bilgi toplumu olarak nitelendirilmektedir. ${ }^{2}$ Bilgi toplumu kavramı, yeni iletişim teknolojileri sayesinde tüm bireylerin bu teknolojilere, bilgilere ulaşabilmesini ayrıca bu teknolojileri kullanabilme imkânının sağlandığı toplumu ifade etmektedir. Böylelikle bilgi kullanımı ve bilgi toplumunda görülen ilerlemeler bireyler ve işletmeler için yeni uygulamalar, oluşumlar, fikirler sunmaktadir. $^{3}$

Ülkeler, kurumlar ve bireyler için önem arz eden bilgi teknolojileri kavramı sanayi devriminden itibaren gündemde olmuştur. Bilgi teknolojileri kavramı, bilginin elde edilerek işlenmesi, saklanması ve dağ1tılması süreçlerinin teknoloji ile gerçekleştirilmesi şeklinde ifade edilmektedir. ${ }^{4}$ Ülkemizde bu kavramın kısaca "BT" şeklinde ifade edildiği görülmektedir.

Bilgi toplumlarında bilgi edinme, kullanma, üretme yeteneğine sahip olan bireyler yetiştirmek giderek önem kazanmaktadır. Bu durumların sonucunda gelişmiş toplumların eğitim ve araştırma alanına daha fazla yatırım yaptığı görülmektedir. ${ }^{5}$

Bilgi teknolojilerinde meydana gelen değişimlerden faydalan diğer bir sektör ise sağlık sektörüdür. $\mathrm{Bu}$ teknolojiler sayesinde sunulan sağlık hizmetinin kalitesi, hızı, güvenliği ve verimliliği artmaktadır. Sağlıkla ilgili merak edilen bilgilerin çoğunluğuna sağlık veri tabanlarından kolaylıkla ulaşılabilmektedir. Ayrıca kişilere ait geçmiş ve güncel bilgilerde veri tabanına kaydedilmekte ve yer, zaman kısitı olmadan bu bilgilere kolaylıkla erişim sağlanmaktadir. $^{6}$

Bu çalışma insan hayatını büyük ölçüde değiştiren, geliştiren ve kolaylaştıran BİT'in Sağlık Bilimleri Fakültesi'nde öğrenim gören geleceğin sağlık çal1şanları için ne denli önemli olduğunu belirlemek, hem özel hayatlarında hem de hizmet sunum esnasında sıklıkla karşılaşacakları bilgi ve iletişim teknolojilerine karşı tutumlarını ölçmek amacıyla yapılmiştır.

\section{MATERYAL VE METOT}

Araştırmanın Tipi ve Etik Yönü: Betimleyici tipte olan bu araştırmanın yürütülebilmesi için Necmettin Erbakan Üniversitesi Sosyal Beşeri Bilimler Etik Kurulundan etik kurul onayları alınmıştır (Tarih: 19.02.2018, karar no: 2018/3). Ayrıca araştırmaya katılan öğrencilerden veri toplama aşamasında sözlü onam alınmıştır.

Araştırmanın Yeri ve Zamanı: Araştırma Konya ilinde ve bu ilde yer alan iki devlet üniversitesinde 2018-2019 yılları arasında yürütülmüştür.

Araştırmanın Evreni ve Örneklemi: Araştırma örneklem seçiminde olasılıklı örnekleme yöntemi olan basit tesadüfi örnekleme yöntemi kullanılmıştır. Ça1ışmamızın örneklemini Necmettin Erbakan Üniversitesi ve Selçuk Üniversitesi Sağlık Bilimleri Fakültesi'nde 3. sınıf lisans eğitimini henüz tamamlamamış 353 öğrenci oluşturmaktadır. Araştırmada sadece 3. sınıf lisans öğrencilerinin tercih edilme sebebi; öğrencilerin bilgi ve iletişim teknolojilerine yönelik derslerin büyük çoğunluğunu 3. sınıfin sonuna kadar tamamlamış olmaları ve bu konuya dair yeterli bilgiye sahip oldukları öngörülmüştür.

Veri Toplama Araçları: Araştırmada veriler "Kişisel Bilgi Formu” ve "BİT Tutum Ölçeği” kullanılarak elde edilmiştir.

Kişisel bilgi formu; araştırmacılar tarafından literatür incelenerek hazırlanan bu formda; katılımcıların demografik özelliklerini belirlemeye yönelik sorular (cinsiyet, yaş, medeni hal, üniversite, bölüm, sınıf, yaşanılan yer, ekonomik düzey) ile bilgi ve iletişim teknolojilerine yönelik görüşlerini içeren toplam 14 soru yer almaktadır.

BiT Tutum Ölçeği; Günbatar tarafindan geliştirilmiş ölçeğin cronbach alfa katsayısı 0,91 olarak saptanmıştır. ${ }^{7}$ Çalışmamızda ölçeğin cronbach alfa katsayısı 0,87 olarak saptanmıştır. Toplam 23 soru içeren ölçeğin; "genel BİT eğilimi”, "sanal ortamda bilgiye erişim”, "bilgisayar donanımı”, “yazılım kullanımı", "sanal ortamda iletişim” olmak üzere beş alt boyutu bulunmaktadır. Ölçekte yer alan ifadeler beşli Likert tipi derecelendirmeye tabi tutulmuştur.

Uygulama: Araştırmaya katılmayı kabul eden öğrencilerin sözel onamları alındıktan sonra yüz yüze görüşme yöntemi ile anket formunu cevaplamaları istenmiş ve bir anketin yanıtlanması ortalama $20 \mathrm{dk}$ sürmüştür. Tüm soruları tam olarak tamamlayan katılımcılar araştırma kapsamına alınmıştır.

Verilerin Değerlendirilmesi: Çalışmada elde edilen verilerin istatistiksel analizleri için SPSS Statistics 
22 programı kullanılmıştır. Öğrencilerin sosyodemografik özellikleri, BİT tutum ölçeği puanlarının tanımlanmasında; frekans, yüzde, aritmetik ortalama standart sapma ve minimum-maksimum değerler kullanılmıştır. Değişkenler arasındaki ilişkiyi tespit etmek için ki-kare testi, değişkenlerin ilişki düzeylerini tespit etmek için ise Cramer's V değerleri incelenmiştir. Değerler 0-1 aralığında değişmektedir. 030 arası değerlerin zayıf, 31-60 arası değerlerin orta, 61-100 arası değerlerin ise güçlü bir ilişkiye sahip olduğu söylenebilir. ${ }^{8}$

Parametrik test varsayımlarının sağlandığı durumlarda bağımsız örneklem $t$ testi ve tek yönlü ANOVA, farklılığa neden olan grubun tespitinde ise Tukey HSD post-hoc testi kullanılmıştır. Sonuçlar \%95 güven aralığında, $\mathrm{p}<0,05$ anlamlılık düzeyinde değerlendirilmiştir.

Araştırmanın Sınırlılıkları: Araştırmanın sadece Konya ilinde yapılması ve sadece Necmettin Erbakan Üniversitesi ile Selçuk Üniversitesi Sağlık Bilimleri Fakültesinde lisans öğrenimi gören 3. sınıf öğrencilerinin kapsama alınması araştırmanın sınırlılıkları arasında yer almaktadır.

\section{BULGULAR}

Araştırma; \%83,9'u (296) kadın ve \%16,1'i (57) erkek olmak üzere toplam 353 öğrencinin katılımıyla yapılmıştır. Öğrencilerin \%59,5'inin Necmettin Erbakan Üniversitesi'nden, \%40,5'inin ise Selçuk Üniversitesi’nden katılım sağladığı görülmüştür. Bölüm bazlı dağılıma bakıldığında ise en fazla (\% $37,1)$ hemşirelik, en az $(\% 7,1)$ beslenme ve diyetetik bölümü öğrencilerinin katılım sağladığı tespit edilmiştir. Öğrencilerin büyük çoğunluğunun $(\% 85,6)$ orta düzey gelir grubunda yer aldığı saptanmıştır. Öğrencilerin yarıdan fazlasının $(\% 67,5)$ interneti günlük 1-5 saat arasında kullandığı ve internete en fazla $(\% 57,8)$ cep telefonundan bağlandı̆̆ miştir (Tablo 1).

Araştırmada katılımcıların günlük hayatta yararlandığı bilgi ve iletişim teknolojisinin en fazla (\%39) cep telefonu, en az $(\% 2,5)$ dijital oynatıcılar olduğu saptanmıştır. Öğrencilerin interneti kullanım amaçlarının; en fazla $(\% 12,4)$ eğlenmek, buna yakın bir oranda $(\% 12,1)$ araştırma yapmak olduğu ve en az $(\% 0,1)$ kullanımın ise internet üzerinden para kazanmak olduğu tespit edilmiştir (Tablo 2).

Katılımcıların ekonomik düzeyi ile internetin günlük kullanım süresi arasında anlamlı $(p=0,001)$ ve düşük düzeyde (Cramer's V değeri $\left.\left(\varphi_{c}\right)=0,180\right)$ bir ilişki tespit edilmiştir. Ekonomik durumu orta, yüksek ve çok yüksek olan katılımcıların, ekonomik durumu kötü olan katılımcılara göre interneti daha fazla kullandığı belirlenmiştir (Tablo 3).

BİT tutum ölçeği toplam puan ortalamalarının cinsiyete göre istatistiksel olarak anlamlı bir şekilde farklılaştığ tespit edilmiştir $(p=0,001)$. Erkeklerin BİT tutum ölçek ortalamalarının $(\overline{\mathrm{x}}=3,69)$ kadınların BİT tutum ölçek ortalamalarından $(\overline{\mathrm{x}}=3,45)$ daha yüksek olduğu belirlenmiştir. BİT tutum ölçeği toplam puan ortalamalarının katılımcıların üniversitelerine göre farklılaşmadığı tespit edilmiştir $(p=0,993)$. BİT tutum ölçeği alt boyutları toplam puan ortalamalarının cinsiyet değişkeni ile donanım alt boyutu arasında anlamlı bir fark olduğu saptanmıştır $(\mathrm{p}=0,000)$. Ayrıca erkeklerin donanım ortalamalarının $(\overline{\mathrm{x}}=2,96)$, kadınların donanım ortalamalarından $(\overline{\mathrm{x}}=2,24)$ daha yüksek olduğu belirlenmiştir. Öğrencilerin üniversiteleri ile BİT tutum ölçeği alt boyutları toplam puan ortalamalarının sadece genel BİT eğilimi ile arasında anlamlı bir fark olduğu sonucuna ulaşılmıştır $(p=0,030)$. Ayrıca Necmettin Erbakan Üniversitesi öğrencilerinin genel BİT eğilimi ortalamalarının $(\overline{\mathrm{x}}=3,90)$, Selçuk Üniversitesi öğrencilerinin genel BİT eğilimi ortalamalarından $(\bar{x}=3,74)$ daha yüksek olduğu belirlenmiştir (Tablo 4).

BİT tutum ölçeği toplam puan ortalamalarının kat1lımcıların bölümlerine göre istatistiksel açıdan anlamlı bir şekilde farklılaştığı görülmektedir $(p=0,012)$. Söz konusu farkın hangi gruptan kaynaklandığını saptamak için yapılan post-hoc analizi sonucunda, farkın sağlık yönetimi bölümü öğrencilerinden kaynaklandığı saptanmıştır. Bölüm değişkeni ile BİT tutum ölçeği alt boyutları toplam puan ortalamalarının sadece yazılım kullanımı ile arasında anlamlı bir fark olduğu tespit edilmiş $(\mathrm{p}=0,004)$ ve söz konusu farkın hangi gruptan kaynaklandığını saptamak için yapılan post-hoc analizi sonucunda, farkın sağlık yönetimi bölümü öğrencilerinden kaynaklandığı belirlenmiştir (Tablo 5).

\section{TARTIŞMA VE SONUÇ}

Çalışmada, katılımcıların günlük interneti kullanım miktarına bakıldığında, çoğunluğunun $(\% 67,5)$ interneti günde ortalama 1-5 saat, \%24,9'unun 6-10 saat kullandığı tespit edilmiştir. Bu bulguya göre çalışmaya katılan öğrencilerin internet kullanım oranının yüksek olduğu söylenebilir. Türkiye İstatistik Kurumu (TÜİK)' nun 'Hanehalkı Bilişim Teknolojileri 
Kullanım Araştırması"na göre bilgisayar ve internet kullanımı 2016 yılında 16-74 yaş grubundaki bireylerde sirasiyla \%54,9 ve \%61,2 iken 2017 yılında bu oranların sırasıyla \%56,6 ve \%66,8'e yükseldiği ifade edilmiştir. Bu veri 1şı ğında günümüz internet çağında gün geçtikçe internet kullanım oranının daha fazla artacağı yorumu yapılabilir.

Çalışmada öğrencilerin interneti kullanım amaçlarının; en fazla $(\% 12,4)$ eğlenmek, buna yakın bir oranda $(\% 12,1)$ araştırma yapmak ve en az $(\% 0,1)$ kullanımın ise internet üzerinden para kazanmak olduğu tespit edilmiştir. Bu bulgu ile farklılık gösteren çalışmalar bulunmaktadır. Alaca ve Yılmaz tarafindan ele alınan çalışmada ${ }^{3}$ genellikle internetin sosyal medya paylaşımları, mesaj gönderme, gazete, dergi ya da online haber gönderme gibi amaçlarla kullanıldığı saptanmıştır. Yirci ve Aydoğar'ın ${ }^{10}$ yapmış oldukları çalışmada ise, üniversite öğrencilerinin bilgi teknolojilerini ilk olarak araştırma yapmak, ikinci sırada ise eğlenme ve iletişim kurma amacıyla kullandıkları sonucuna ulaşmaları çalışmalardaki sonuçların benzer olmakla birlikte önem sıralarının farklılık gösterdiğini ortaya koymaktadır.

Çalışmada katılımcıların büyük çoğunluğunun internete cep telefonundan $(\% 57,8)$, en az ise $(\% 1,1)$ internet kafeden bağlandığ gu üzerinde günümüzde cep telefonuna sahip olma oranının artmasının, cep telefonundan internete erişimin daha kolay ve ucuz olmasının etkisi olduğu söylenebilir. Benzer bir çalışmada internete cep telefonundan bağlanma oranının 2015 yılından itibaren arttığı belirlenmiştir. ${ }^{3}$ Çalışmada öğrencilerin internete bağlandığı yer olarak ikinci sırada ev faktörünün $(\% 21,8)$ geldiği görülmüştür. Bu bulgu üzerinde etkisi olan faktörün günümüzde evden internet alt yapısının iyileştirilmesi ve makul fiyatlar ile sunulması olduğu söylenebilir. Türkiye İstatistik Kurumu'nun (TÜİK) yapmış olduğu araştırmaya ${ }^{9}$ göre, 2016 yılının Nisan ayında hanelerin \%76,3'ü evden internete erişme imkânına sahip iken, 2017 yılının aynı ayında bu oranının \%80,7'ye yükseldiğini ifade etmesi çalışmayı destekler niteliktedir.

Çalışmada cinsiyet ile BİT kullanımı arasında anlamlı bir farklılık bulunmamıştır. Çalışma bulgumuz ile farklılık gösteren araştırmalar bulunmaktadır. Yirci ve Aydoğar ele aldıkları çalışmada ${ }^{10}$ erkeklerin kadınlara nazaran BİT'te daha fazla zaman harcadığını saptamıştır. Eryılmaz tarafından ele alınan çalışmada $^{11}$ erkek öğrencilerin BİT yeterlik düzeyinin kadınlardan daha yüksek bir seviyede olduğu tespit edilmiştir.

Çalışmada katılımcıların ekonomik düzeyi ile inter- netin günlük kullanım süresi arasında anlamlı ve düşük düzeyde bir ilişki tespit edilmiştir. Bu bulgu, katılımcıların gelir seviyesinin internete erişimi etkilediğini göstermektedir. Benzer bir çalışmada, düşük gelir ve düşük eğitim seviyesinde olan birey ve grupların BİT'ten yeterli şekilde faydalanamadıkları belirtilmiştir. $^{12}$

Çalışmada BİT tutum ölçeği toplam puan ortalamaları ve alt boyutları toplam puan ortalamalarının sadece yazılım kullanımı faktörü ile katılımcıların bölümleri arasında anlamlı bir farklılık tespit edilmiş, sağlık yönetimi bölümü öğrencilerinin bu farkl1lığa neden olduğu saptanmıştır. Bu bulguya göre, sağlık yönetimi bölümü öğrencilerinin diğer bölümlerdeki öğrencilere nazaran BİT'e karşı daha yüksek bir tutuma sahip olduğu söylenebilir.

Sonuç olarak; Çalışmada öğrencilerin BİT’i hem eğitim hem de güncel hayatlarında kullanmaya karşı olumlu bir tutum içerisinde oldukları tespit edilmiştir. Ayrıca Necmettin Erbakan Üniversitesi öğrencilerinin ve Selçuk Üniversitesi öğrencilerinin BİT’e karşı benzer tutuma sahip oldukları saptanmıştır. Yapılan literatür taramasında da BİT'in eğitim alanında ve diğer alanlarda kullanımının zorunluluk haline geldiğinin ifade edilmesi, eğitimde bilgi teknolojilerinden faydalanmanın öğrencilerin dersten daha fazla verim almasına ve derste daha etkin olmasına katkı sağladığının ortaya konulması BİT'in eğitim alanında ne kadar önemli olduğunu göstermektedir.

Etik Komite Onayl: Necmettin Erbakan Üniversitesi Sosyal Beşeri Bilimler Etik Kurulundan etik kurul onayları alınmıştır (Tarih: 19.02.2018, karar no: 2018/3). Araştırmaya katılan öğrencilerden veri toplama aşamasında sözlü onam alınmıştır.

Çıkar Çatışması: Yazarlar çıkar çatışması bildirmemektedir.

Yazar Katkıları: Fikir - DT, YYİ; Veri toplanması ve/veya işlemesi - DT; Analiz ve/veya yorum - DT, YYİ; Literatür taraması - DT; Yazıyı yazan - DT; Eleştirel inceleme-YYİ.

Hakem değerlendirmesi: D1ş bağımsız.

\section{KAYNAKLAR}

1. Arat R. Ortaokullarda kullanılan bilgi iletişim teknolojilerinin öğretmenlerin sınıf yönetimi becerilerine etkisi. Akdeniz Üniversitesi Eğitim Bilimleri Anabilim Dalı, Yüksek Lisans Tezi. Antalya, Türkiye. 2015.

2. Çakır O. Otel işletmelerinde bilgi teknolojileri kullanımının görev teknoloji uyum modeli kapsa- 
mında değerlendirilmesi: İstanbul' daki 4 ve 5 yıldızlı oteller üzerine bir araştırma. Sakarya Üniversitesi Turizm İşletmeciliği Anabilim Dalı, Yüksek Lisans Tezi. Sakarya, Türkiye. 2011.

3. Alaca E, Yılmaz B. Bilgi ve iletişim teknolojilerinin kullanımı ve bilgi toplumuna dönüşüm: Türkiye'de durum. Türk Kütüphaneciliği Dergisi. 2016;30(3):507-523.

4. Yavuz E. Bilgi teknolojilerinin kurumlarda örgütsel performans üzerindeki etkileri ve Konya meslek odaları araştırması. KTO Karatay Üniversitesi İşletme Anabilim Dalı, Yüksek Lisans Tezi. Konya, Türkiye. 2016.

5. Büyükbaykal CI. Communication technologies and education in the information age. ProcediaSocial and Behavioral Sciences. 2015;174:636640.

6. Uysal DY. Bilgi teknolojileri yatırımları, bilgi teknolojileri performansı ve karar verme ilişkisi üzerine bir araştırma. İstanbul Üniversitesi İşletme Anabilim Dalı, Yüksek Lisans Tezi. İstanbul, Türkiye. 2009.

7. Günbatar MS. Bilgi ve iletişim teknolojilerine yönelik bir tutum ölçeği geliştirme çalışması. Ahi Evran Üniversitesi Kırşehir Eğitim Fakültesi Dergisi. 2014;15(1):121-135.

8. Özbay A. Çapraz tablo analizi nasıl yapılır? Pratik bir açıklama. Türkiyat Araştırmaları. 2008;(9):459-470.

9. Türkiye İstatistik Kurumu (TÜIK) Hane halk1 Bilişim Teknolojileri Kullanım Araştırması 2017. http://www.tuik.gov.tr/PreHaberBultenleri.do? id=24862. Erişim tarihi 5 Kasım 2018.

10. Yirci R, Aydoğar N. Üniversite öğrencilerinin bilgi ve iletişim teknolojilerine yönelik tutumlarının bazı değişkenler açısından incelenmesi. Ulakbilge. 2017;5(18):2175-2203.

11.Eryılmaz S. Öğrencilerin bilgi ve iletişim teknolojileri yeterliliklerinin belirlenmesi: Gazi Üniversitesi, Turizm Fakültesi örneği. Elektronik Sosyal Bilimler Dergisi. 2018;17(65):37-49.

12. Seferoğlu SS, Avcı Ü, Kalaycı E. Sayısal uçurum: Türkiye'deki durum ve mücadelede uygulanabilecek politikalar. 25. Ulusal Bilişim Kurultayı. 19-21 Kasım 2008, Ankara/Türkiye. 
Tablo 1. Öğrencilerin tanımlayıcı özelliklerinin dağılımı.

\begin{tabular}{|c|c|c|}
\hline Tanımlayıcı özellikle & $\mathbf{N}^{*}$ & $\%$ \\
\hline \multicolumn{3}{|l|}{ Cinsiyet } \\
\hline Kadin & 296 & 83,9 \\
\hline Erkek & 57 & 16,1 \\
\hline Toplam & 353 & 100,0 \\
\hline \multicolumn{3}{|c|}{ Üniversite } \\
\hline Necmettin Erbakan Üniversitesi & 210 & 59,5 \\
\hline Selçuk Üniversitesi & 143 & 40,5 \\
\hline Toplam & 353 & 100,0 \\
\hline \multicolumn{3}{|c|}{ Bölüm } \\
\hline Beslenme ve Diyetetik & 25 & 7,1 \\
\hline Çocuk Gelişimi & 44 & 12,5 \\
\hline Fizyoterapi ve Rehabilitasyon & 58 & 16,4 \\
\hline Hemşirelik & 131 & 37,1 \\
\hline Sağlık Yönetimi & 60 & 17,0 \\
\hline Sosyal Hizmet & 35 & 9,9 \\
\hline Toplam & 353 & 100,0 \\
\hline \multicolumn{3}{|c|}{ Ekonomik Düzey } \\
\hline Çok Düşük & 1 & 0,3 \\
\hline Düşük & 25 & 7,1 \\
\hline Orta & 302 & 85,6 \\
\hline Yüksek & 21 & 5,9 \\
\hline Çok Yüksek & 3 & 0,8 \\
\hline Cevapsız & 1 & 0,3 \\
\hline Toplam & 353 & 100,0 \\
\hline \multicolumn{3}{|c|}{ Günlük İnternetin Kullanım Miktarı (Saat) } \\
\hline $1-5$ & 238 & 67,5 \\
\hline $6-10$ & 88 & 24,9 \\
\hline $11-15$ & 21 & 5,9 \\
\hline $16-18$ & 6 & 1,7 \\
\hline Toplam & 353 & 100,0 \\
\hline \multicolumn{3}{|c|}{ İnternete Bağlanılan Yer } \\
\hline Ev & 77 & 21,8 \\
\hline Fakülte & 29 & 8,2 \\
\hline Internet Kafe & 4 & 1,1 \\
\hline Cep Telefonu & 204 & 57,8 \\
\hline Diğer & 39 & 11,1 \\
\hline Toplam & 353 & 100,0 \\
\hline
\end{tabular}


Tablo 2. Öğrencilerin günlük hayatta yararlandığı bilgi ve iletişim teknolojilerinin dağılımı.

\begin{tabular}{|c|c|c|}
\hline & $\mathbf{N}^{*}$ & $\%$ \\
\hline \multicolumn{3}{|c|}{ Günlük Havatta Yararlanılan Bilgi İletisim Teknolojileri } \\
\hline Cep Telefonu & 349 & 39,0 \\
\hline Dijital Kayıt Cihazları & 24 & 2,7 \\
\hline Dijital Oynatıcılar & 22 & 2,5 \\
\hline Dijital Kamera/Fotoğraf Makinesi & 64 & 7,1 \\
\hline Masaüstü Bilgisayar & 159 & 17,8 \\
\hline Notebook/Netbook & 118 & 13,2 \\
\hline Tablet & 82 & 9,2 \\
\hline Taşınabilir Disk & 76 & 8,5 \\
\hline Toplam & 894 & 100,0 \\
\hline \multicolumn{3}{|c|}{ İnterneti Kullanım Amaçları } \\
\hline Elektronik Posta Almak & 114 & 4,8 \\
\hline Haber Okumak-Medyayı İzlemek & 244 & 10,4 \\
\hline Eğlenmek & 291 & 12,4 \\
\hline Müzik Dinlemek-Resim Yapmak & 257 & 10,9 \\
\hline Chat Yapmak & 147 & 6,2 \\
\hline Oyun & 133 & 5,6 \\
\hline Yarışmalara Katılmak & 11 & 0,5 \\
\hline Bankacılık İşlemleri-Alışveriş & 168 & 7,1 \\
\hline Şans Oyunları Oynamak & 19 & 0,8 \\
\hline İnternet Üzerinden Para Kazanmak & 3 & 0,1 \\
\hline Araştırma Yapmak & 284 & 12,1 \\
\hline Ödev Yapmak & 265 & 11,3 \\
\hline Yazı Yazmak & 71 & 3,0 \\
\hline Yabancı Dilimi İlerletmek & 53 & 2,3 \\
\hline Ders Esnasında Kullanmak & 147 & 6,2 \\
\hline Uzaktan Eğitime Devam Etmek & 17 & 0,7 \\
\hline Akademik Araştırmalar & 98 & 4,2 \\
\hline Diğer & 32 & 1,4 \\
\hline Toplam & 2354 & 100,0 \\
\hline
\end{tabular}

*: Çoklu yanıtlı sorularda toplam örneklem sayısı. 
Tablo 3. Öğrencilerin ekonomik düzeyi ile internetin günlük kullanımı arasındaki ilişkinin değerlendirilmesi.

\begin{tabular}{|c|c|c|c|c|c|c|c|c|c|c|c|c|}
\hline \multirow{3}{*}{\begin{tabular}{|l|} 
\\
Günlük \\
İternetin \\
Kullanım \\
Miktarı \\
(Saat)
\end{tabular}} & \multicolumn{10}{|c|}{ Ekonomik Düzey } & & \\
\hline & \multicolumn{2}{|c|}{ Çok Düşük } & \multicolumn{2}{|c|}{ Düşük } & \multicolumn{2}{|c|}{ Orta } & \multicolumn{2}{|c|}{ Yüksek } & \multicolumn{2}{|c|}{ Çok Yüksek } & \multicolumn{2}{|c|}{ Toplam } \\
\hline & $\mathbf{N}$ & $\%$ & $\mathbf{N}$ & $\%$ & $\mathbf{N}$ & $\%$ & $\mathbf{N}$ & $\%$ & $\mathbf{N}$ & $\%$ & $\mathbf{N}$ & $\%$ \\
\hline $1-5$ & $\begin{array}{l}0 \\
0\end{array}$ & $\begin{array}{l}0,0 \\
0,0\end{array}$ & $\begin{array}{l}18 \\
18\end{array}$ & $\begin{array}{c}7,6 \\
72,0\end{array}$ & $\begin{array}{l}204 \\
204\end{array}$ & $\begin{array}{l}86,1 \\
67,5\end{array}$ & $\begin{array}{l}13 \\
13\end{array}$ & $\begin{array}{c}5,5 \\
61,9\end{array}$ & $\begin{array}{l}2 \\
2\end{array}$ & $\begin{array}{c}0,8 \\
66,7\end{array}$ & $\begin{array}{l}237 \\
237\end{array}$ & $\begin{array}{c}100,0 \\
67,3\end{array}$ \\
\hline $6-10$ & $\begin{array}{l}1 \\
1 \\
\end{array}$ & $\begin{array}{c}1,1 \\
100,0 \\
\end{array}$ & $\begin{array}{l}6 \\
6 \\
\end{array}$ & $\begin{array}{c}6,8 \\
24,0 \\
\end{array}$ & $\begin{array}{l}78 \\
78 \\
\end{array}$ & $\begin{array}{l}88,6 \\
25,8 \\
\end{array}$ & $\begin{array}{l}3 \\
3 \\
\end{array}$ & $\begin{array}{c}3,4 \\
14,3 \\
\end{array}$ & $\begin{array}{l}0 \\
0 \\
\end{array}$ & $\begin{array}{l}0,0 \\
0,0\end{array}$ & $\begin{array}{l}88 \\
88 \\
\end{array}$ & $\begin{array}{l}100,0 \\
25,0 \\
\end{array}$ \\
\hline $11-15$ & $\begin{array}{l}0 \\
0\end{array}$ & $\begin{array}{l}0,0 \\
0,0\end{array}$ & $\begin{array}{l}1 \\
1 \\
\end{array}$ & $\begin{array}{l}4,8 \\
4,4 \\
\end{array}$ & $\begin{array}{l}17 \\
17 \\
\end{array}$ & $\begin{array}{c}81,0 \\
5,6\end{array}$ & $\begin{array}{l}3 \\
3 \\
\end{array}$ & $\begin{array}{l}14,3 \\
14,3 \\
\end{array}$ & $\begin{array}{l}0 \\
0 \\
\end{array}$ & $\begin{array}{l}0,0 \\
0,0\end{array}$ & $\begin{array}{l}21 \\
21 \\
\end{array}$ & $\begin{array}{c}100,0 \\
6,0 \\
\end{array}$ \\
\hline $16-18$ & $\begin{array}{l}0 \\
0\end{array}$ & $\begin{array}{l}0,0 \\
0,0\end{array}$ & $\begin{array}{l}0 \\
0 \\
\end{array}$ & $\begin{array}{l}0,0 \\
0,0\end{array}$ & $\begin{array}{l}3 \\
3 \\
\end{array}$ & $\begin{array}{c}50,0 \\
1,0 \\
\end{array}$ & $\begin{array}{l}2 \\
2 \\
\end{array}$ & $\begin{array}{c}33,3 \\
9,5\end{array}$ & $\begin{array}{l}1 \\
1 \\
\end{array}$ & $\begin{array}{l}16,7 \\
33,3 \\
\end{array}$ & $\begin{array}{l}6 \\
6 \\
\end{array}$ & $\begin{array}{c}100,0 \\
1,7 \\
\end{array}$ \\
\hline Toplam & $\begin{array}{l}1 \\
1 \\
\end{array}$ & $\begin{array}{c}0,3 \\
100,0\end{array}$ & $\begin{array}{l}25 \\
25 \\
\end{array}$ & $\begin{array}{c}7,1 \\
100,0 \\
\end{array}$ & $\begin{array}{l}302 \\
302 \\
\end{array}$ & $\begin{array}{c}85,8 \\
100,0 \\
\end{array}$ & $\begin{array}{l}21 \\
21 \\
\end{array}$ & $\begin{array}{c}6,0 \\
100,0\end{array}$ & $\begin{array}{l}3 \\
3 \\
\end{array}$ & $\begin{array}{c}0,9 \\
100,0\end{array}$ & $\begin{array}{l}352 \\
352 \\
\end{array}$ & $\begin{array}{l}100,0 \\
100,0 \\
\end{array}$ \\
\hline$X^{2}=34,279^{*}$ & & & & & & 0,001 & & & & & & $180^{k * k}$ \\
\hline
\end{tabular}

*: Pearson Chi-Square; ${ }^{* *}$ Cramer’s V değeri $\left(\varphi_{c}\right)$ : Değişkenler arasındaki ilişki düzeyi; N: Çoklu yanıtlı sorularda toplam örneklem sayısı. 
Tablo 4. Bilgi ve iletişim teknolojileri tutum ölçeği toplam puan ve alt boyut ortalamalarının değişkenlere göre farklılaşma dağılımları.

\begin{tabular}{|c|c|c|c|}
\hline \multicolumn{4}{|c|}{ BİT Tutum Ölçeği } \\
\hline Cinsiyet & $\overline{\boldsymbol{x}} \pm \mathbf{S s}$ & $\mathbf{t}$ & $\mathbf{p}$ \\
\hline Kadın & $3,45 \pm 0,50$ & \multirow[b]{2}{*}{$-3,244$} & \multirow[b]{2}{*}{0,001} \\
\hline Erkek & $3,69 \pm 0,57$ & & \\
\hline Üniversite & $\overline{\boldsymbol{x}} \pm \mathbf{S s}$ & $\mathbf{t}$ & $\mathbf{p}$ \\
\hline Necmettin Erbakan Üniversitesi & $3,48 \pm 0,52$ & \multirow[b]{2}{*}{0,009} & \multirow[b]{2}{*}{0,993} \\
\hline Selçuk Üniversitesi & $3,48 \pm, 53$ & & \\
\hline \multicolumn{4}{|c|}{ Donanım } \\
\hline Cinsiyet & $\overline{\boldsymbol{x}} \pm \mathbf{S s}$ & $\mathbf{t}$ & $\mathbf{p}$ \\
\hline Kadın & $2,24 \pm 1,04$ & \multirow[b]{2}{*}{2,24} & \multirow{2}{*}{$1, \overline{0} 4$} \\
\hline Erkek & $2,96 \pm 1,28$ & & \\
\hline \multicolumn{4}{|c|}{ Genel BİT Eğilimi } \\
\hline Üniversite & $\overline{\boldsymbol{x}} \pm \mathbf{S s}$ & $\mathbf{t}$ & p \\
\hline Necmettin Erbakan Üniversitesi & $3,90 \pm 0,64$ & \multirow[b]{2}{*}{2,182} & \multirow[b]{2}{*}{0,030} \\
\hline Selçuk Üniversitesi & $3,74 \pm 0,72$ & & \\
\hline
\end{tabular}

$\overline{\boldsymbol{x}} \pm$ Ss: Ortalama \pm Standart Sapma. 
Tablo 5. Bilgi ve iletişim teknolojileri tutum ölçeği toplam puan ve alt boyut ortalamalarının öğrencilerin bölümlerine göre farklılaşma dağılımları.

\begin{tabular}{|c|c|c|c|c|c|c|}
\hline \multicolumn{7}{|c|}{ BİT Tutum Ölçeği } \\
\hline Bölümler & $\overline{\boldsymbol{x}} \pm \mathbf{S S}$ & Min. & Max. & $\mathbf{F}$ & $\mathbf{p}$ & Post-Hoc \\
\hline Beslenme ve Diyetetik (a) & $3,45 \pm 0,35$ & 2 & 4 & \multirow{6}{*}{2,968} & \multirow{6}{*}{0,012} & \multirow{6}{*}{$\mathrm{e}>\mathrm{d}, \mathrm{a}, \mathrm{f}, \mathrm{b}, \mathrm{c}$} \\
\hline Çocuk Gelişimi (b) & $3,39 \pm 0,59$ & 1 & 5 & & & \\
\hline Fizyoterapi ve Rehabilitasyon (c) & $3,35 \pm 0,59$ & 1 & 4 & & & \\
\hline Hemşirelik (d) & $3,50 \pm 0,53$ & 2 & 5 & & & \\
\hline Sağlık Yönetimi (e) & $3,69 \pm 0,46$ & 2 & 5 & & & \\
\hline Sosyal Hizmet (f) & $3,44 \pm 0,41$ & 2 & 5 & & & \\
\hline \multicolumn{7}{|c|}{ Yazılım Kullanımı } \\
\hline Bölümler & $\overline{\mathbf{x}} \pm \mathbf{S s}$ & Min. & Max. & $\mathbf{F}$ & $\mathbf{p}$ & Post-Hoc \\
\hline Beslenme ve Diyetetik (a) & $3,52 \pm 0,58$ & 2 & 4 & \multirow{6}{*}{3,517} & \multirow{6}{*}{0,004} & \multirow{6}{*}{$e>f, a, b, d, c$} \\
\hline Çocuk Gelişimi (b) & $3,51 \pm 0,84$ & 2 & 5 & & & \\
\hline Fizyoterapi ve Rehabilitasyon (c) & $3,23 \pm 0,80$ & 1 & 5 & & & \\
\hline Hemşirelik (d) & $3,47 \pm 0,80$ & 1 & 5 & & & \\
\hline Sağlık Yönetimi (e) & $3,80 \pm 0,58$ & 2 & 5 & & & \\
\hline Sosyal Hizmet (f) & $3,53 \pm 0,64$ & 2 & 5 & & & \\
\hline
\end{tabular}

$\overline{\mathrm{X}} \pm$ SS: Ortalama \pm Standart Sapma; a, b, c, d, e, f: Post-hoc testinde gruplar arasındaki değişkenler. 